\title{
Ejector Enhanced Pulsejet Based Pressure Gain Combustors: An Old Idea With a New Twist
}

\section{Daniel E. Paxson}

Glenn Research Center, Cleveland, Ohio

Kevin T. Dougherty

QSS Group, Inc., Cleveland, Ohio 
Since its founding, NASA has been dedicated to the advancement of aeronautics and space science. The NASA Scientific and Technical Information (STI) Program Office plays a key part in helping NASA maintain this important role.

The NASA STI Program Office is operated by Langley Research Center, the Lead Center for NASA's scientific and technical information. The NASA STI Program Office provides access to the NASA STI Database, the largest collection of aeronautical and space science STI in the world. The Program Office is also NASA's institutional mechanism for disseminating the results of its research and development activities. These results are published by NASA in the NASA STI Report Series, which includes the following report types:

- $\quad$ TECHNICAL PUBLICATION. Reports of completed research or a major significant phase of research that present the results of NASA programs and include extensive data or theoretical analysis. Includes compilations of significant scientific and technical data and information deemed to be of continuing reference value. NASA's counterpart of peerreviewed formal professional papers but has less stringent limitations on manuscript length and extent of graphic presentations.

- TECHNICAL MEMORANDUM. Scientific and technical findings that are preliminary or of specialized interest, e.g., quick release reports, working papers, and bibliographies that contain minimal annotation. Does not contain extensive analysis.

- CONTRACTOR REPORT. Scientific and technical findings by NASA-sponsored contractors and grantees.
- CONFERENCE PUBLICATION. Collected papers from scientific and technical conferences, symposia, seminars, or other meetings sponsored or cosponsored by NASA.

- SPECIAL PUBLICATION. Scientific, technical, or historical information from NASA programs, projects, and missions, often concerned with subjects having substantial public interest.

- TECHNICAL TRANSLATION. Englishlanguage translations of foreign scientific and technical material pertinent to NASA's mission.

Specialized services that complement the STI Program Office's diverse offerings include creating custom thesauri, building customized databases, organizing and publishing research results ... even providing videos.

For more information about the NASA STI Program Office, see the following:

- Access the NASA STI Program Home Page at http://www.sti.nasa.gov

- E-mail your question via the Internet to help@sti.nasa.gov

- Fax your question to the NASA Access Help Desk at 301-621-0134

- Telephone the NASA Access Help Desk at 301-621-0390

- Write to:

NASA Access Help Desk

NASA Center for AeroSpace Information 7121 Standard Drive

Hanover, MD 21076 
NASA/TM-2005-213854

\section{Ejector Enhanced Pulsejet Based Pressure Gain Combustors: An Old Idea With a New Twist}

\section{Daniel E. Paxson}

Glenn Research Center, Cleveland, Ohio

Kevin T. Dougherty

QSS Group, Inc., Cleveland, Ohio

Prepared for the

41st Joint Propulsion Conference and Exhibit

cosponsored by the AIAA, ASME, SAE, and ASEE

Tucson, Arizona, July 10-13, 2005

National Aeronautics and

Space Administration

Glenn Research Center 


\section{Acknowledgments}

This work was supported by the NASA Glenn Research Center's Constant Volume Combustion Cycle Engine

Project (CVCCE). The authors wish to thank the laboratory technicians and mechanics, Robert Pelaez,

Edward Pluta, Mark Robinson, and Roger Scheman for their invaluable assistance in getting and keeping this experiment operational.

This report is a formal draft or working

paper, intended to solicit comments and ideas from a technical peer group.

This report contains preliminary

findings, subject to revision as analysis proceeds.

This work was sponsored by the Low Emissions Alternative

Power Project of the Vehicle Systems Program at the NASA Glenn Research Center.

Available from

NASA Center for Aerospace Information 7121 Standard Drive

Hanover, MD 21076
National Technical Information Service 5285 Port Royal Road Springfield, VA 22100 


\title{
Ejector Enhanced Pulsejet Based Pressure Gain Combustors: An Old Idea With a New Twist
}

\author{
Daniel E. Paxson \\ National Aeronautics and Space Administration \\ Glenn Research Center \\ Cleveland, Ohio 44135 \\ Kevin T. Dougherty \\ QSS Group, Inc. \\ Cleveland, Ohio 44135
}

\begin{abstract}
An experimental investigation of pressure-gain combustion for gas turbine application is described. The test article consists of an off-the-shelf valved pulsejet, and an optimized ejector, both housed within a shroud. The combination forms an effective 'can' combustor across which there is a modest total pressure rise rather than the usual loss found in conventional combustors. Although the concept of using a pulsejet to affect semi-constant volume (i.e., pressure-gain) combustion is not new, that of combining it with a well designed ejector to efficiently mix the bypass flow is. The result is a device which to date has demonstrated an overall pressure rise of approximately 3.5 percent at an overall temperature ratio commensurate with modern gas turbines. This pressure ratio is substantially higher than what has been previously reported in pulsejet-based combustion experiments. Flow non-uniformities in the downstream portion of the device are also shown to be substantially reduced compared to those within the pulsejet itself. The standard deviation of total pressure fluctuations, measured just downstream of the ejector was only 5.0 percent of the mean. This smoothing aspect of the device is critical to turbomachinery applications since turbine performance is, in general, negatively affected by flow non-uniformities and unsteadiness. The experimental rig will be described and details of the performance measurements will be presented. Analyses showing the thermodynamic benefits from this level of pressure-gain performance in a gas turbine will also be assessed for several engine types. Issues regarding practical development of such a device are discussed, as are potential emissions reductions resulting from the rich burning nature of the pulsejet and the rapid mixing (quenching) associated with unsteady ejectors.
\end{abstract}

\section{Introduction}

Gas turbine engines utilizing conventional 'constant pressure' combustion actually suffer a loss in total pressure across the combustor. This is due partly to unavoidable thermodynamic losses associated with heating a fluid at finite Mach number, and partly due to aerodynamic losses associated with the geometrically convoluted flow path (e.g., liner cooling, mixing requirements, etc.). Typical combustor losses range from 4 to 8 percent of the total pressure delivered from the upstream compressor (ref. 1). The loss in total pressure yields lower work potential for the gas entering the downstream turbine. The resulting performance loss to the engine in terms of reduced specific thrust and/or increased specific fuel consumption is not insignificant. The effect of this loss, or more to the point, the benefit of reducing it, is illustrated in figure 1. This figure shows calculated reduction in specific fuel consumption (SFC) as a function of combustor pressure ratio for a small, uncooled turbojet engine, and for a high bypass turbofan engine flying at an altitude of approximately $30 \mathrm{kft}$., and a Mach number of 0.8 . The relevant engine parameters used in the calculations are listed in the appendix. The baseline engine in each case has a combustor pressure loss of 5 percent. The calculations were done using a simple cycle deck based on the analysis methods outlined in reference 2. In each case the specific thrust was held constant by either lowering the turbine inlet temperature (turbojet), or increasing the fan bypass ratio (turbofan) as the combustor pressure ratio rose. Details of the straightforward calculations are omitted here, as the intention is to illustrate a trend rather than to absolutely quantify. 


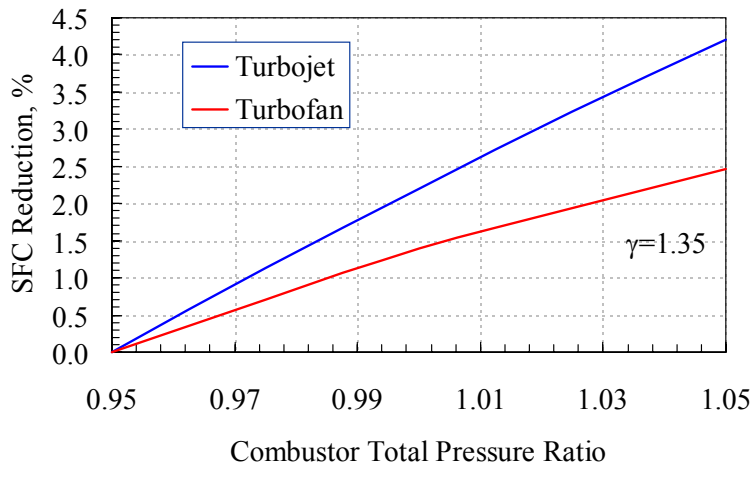

Figure 1.- Reduction in Specific Fuel Consumption as a function of combustor pressure ratio for a small, uncooled turbojet engine, and a high bypass turbofan engine at an altitude of approximately $30 \mathrm{kft}$., and Mach 0.8 cruise.

past (refs. 3 to 6) and near present (refs. 7 and 8). In every investigation, pressure-gain is achieved, either analytically or experimentally, through some approximation of a constant-volume combustion process. As a result, every concept is intermittent (unsteady), though cyclic, in some way. This fact yields a combustor exit flow that is unsteady to varying degrees. Since unsteadiness is generally regarded as a detriment to the performance of downstream turbomachinery, its presence tends to detract from the thermodynamic benefits of the pressure-gain. Therefore it is desirable in any intermittent combustion process to minimize unsteadiness in the exhaust path.

Pressure-gain combustion concepts vary widely in mechanical complexity and theoretical (or realizable) pressure ratio for a given overall temperature ratio (i.e., the amount of fuel added). Generally, and arguably, overall pressure ratio scales with complexity. The higher the potential pressure-gain, the more complex the device tends. Practically speaking however, higher complexity scales with larger developmental risk, time, and difficulty. It is for this reason, perhaps, that the high payoff pressure-gain concepts such as wave rotor, and detonation-based systems remain largely on paper, while the lower payoff concepts, such as those using pulsejets have been demonstrated. Of the latter concepts, unfortunately, the experiments have tended to yield performance levels that are too low to justify further development, despite their relative simplicity. One reason seems to be that the effluent from a pulsejet is far too hot for any turbine to tolerate and must therefore be mixed with some bypass flow. This is typically a loss-filled process and substantially degrades the overall performance.

This paper explores the potential of a pulsejet-driven, pressure-gain combustor in an experiment which capitalizes on the demonstrated ability of properly designed, unsteady ejectors (i.e., augmentors) to efficiently entrain, mix, and smooth secondary flows (refs. 9 and 10). In previous experiments, ejectors driven by unsteady thrust sources have demonstrated exceptionally high thrust augmentation levels. Thrust augmentation is defined as the total thrust of the ejector and driver divided by the thrust of the driver alone. Levels near 2.0 have been reported in the past (ref. 11), and observed more recently when the driver was a pulsejet (refs. 9 and 12). It was purported that if both the pulsejet and ejector were placed within a shroud, the ejector pumping action which normally yields such high thrust augmentation could instead be used to raise the total pressure. This experiment was designed to investigate that proposition. The results which follow will demonstrate that it is indeed true. To date an overall stagnation pressure ratio of 1.037 has been demonstrated while operating with a total temperature ratio of approximately 2.2. This temperature ratio is typical for a many gas turbine combustors. While this is a modest pressure ratio, it appears to be substantially higher than what has been demonstrated in previous pulsejet-based experiments (1.005 to 1.02$)$.

The experimental setup is presented in detail, including relevant instrumentation. Results are being presented showing performance with various ejector configurations, and at different operating conditions. Additional results and discussion are presented from the ejector yielding the highest performance. The paper concludes with an argument suggesting that this type of pressure-gain combustor may also have the potential for low-emissions. 


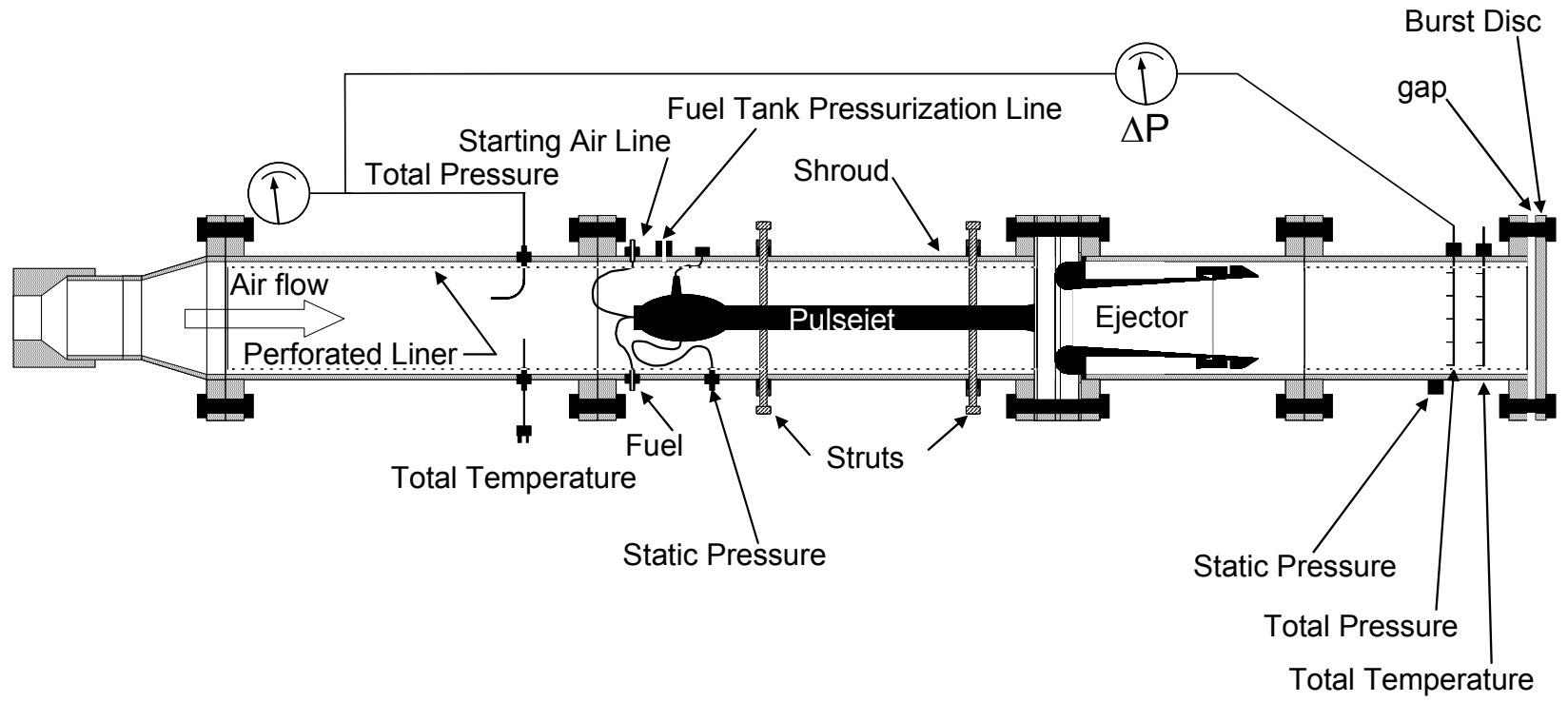

Figure 2.-Pulsejet-driven, pressure-gain combustor rig schematic. The rendering is approximately to scale.

\section{Description of the Experiment}

The experimental rig is shown schematically in figure 2, with relevant components labeled. Air enters the shroud on the left through a regulated 2.0 in. diameter supply line. A portion of the incoming air then passes through the pulsejet, where it is mixed with fuel and reacted according to the cyclic, self-aspirating, resonant process of operation. A large portion of the incoming air bypasses the pulsejet and enters the ejector. Here it is mixed with and pumped by the hot gas exiting the pulsejet. The mixed flow then passes from the ejector into the downstream portion of the shroud containing instrumentation for measuring temperature, time-averaged total pressure, and total pressure fluctuations. Details of the instrumentation and other major rig components will be given following the overall flowpath description. After passing over the instrumentation, the mixed flow exits the rig to the ambient surroundings via a small opening or gap between the terminating flange of the shroud and a specially designed flange blank, which also serves as a safety burst disk. The size of the exhaust gap can be varied using spacers and, in combination with the regulated overall airflow, serves to establish the pressure inside the shroud. Note that the split in airflow between pulsejet and ejector cannot be regulated in this experiment. It is governed by the operation of the pulsejet and the entrainment characteristics of the ejector.

\section{A. Pulsejet}

The pulsejet used in the experiment is based on a commercially available design made by the Dynajet Corporation. A schematic of the device is shown in figure 3, with relevant dimensions and components labeled. The valve body is made from aluminum. The combustion chamber and tailpipe section are made from Inconel. The valve 'petals' are made from blued spring steel. The unit operates on gasoline, at a nominal frequency of $220 \mathrm{~Hz}$., and generates approximately $4.25 \mathrm{lb}_{\mathrm{f}}$ thrust statically in the open air. Starting requires a spark plug (driven by a $60 \mathrm{~Hz}$. high voltage supply), and several short bursts of relatively high pressure air supplied through the starting air line shown in figure 3. Once resonant operation is established, both are terminated. Descriptions of resonant operation may be found in the literature (ref. 13), and as such, will not be presented here. The fuel supply system for the device is of the venturi-type. The fuel tank is external to the rig. A line leads from it, through a remotely operated, on-off valve, to the inlet junction shown in figure 3. The fuel tank head is pressurized to the shroud internal pressure via an air line as shown in figure 2.

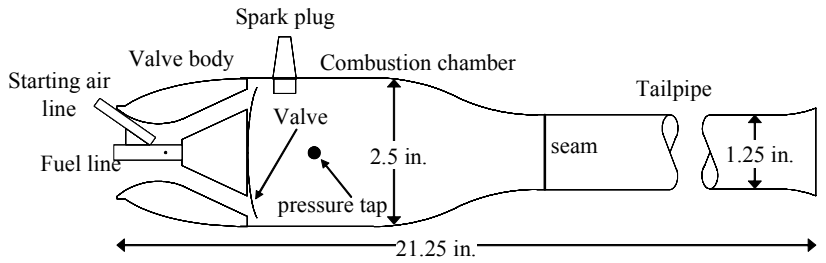

Figure 3.- Schematic of the pulsejet device used in the experiment. 


\section{B. Ejectors}

Several ejectors of various lengths and diameters were tested. All had circular cross-section, and were constructed from aluminum. Three diameters were used, $\mathrm{D}=2.2,3.0$, and 4.0 in. Testing was also done with no ejector present which, given the 6.0 in. shroud diameter could be considered as a fourth ejector diameter. For each diameter tested, a modular ejector body was available as shown in figure 4(a). Two center sections of different length were constructed thereby allowing testing of four total ejector lengths (no center section, short center section, long center section, and coupled center sections). Testing was also performed on a tapered ejector as shown in figure 4(b). The diameter at the end of the inlet was $3.0 \mathrm{in}$. This ejector was also constructed from modular sections allowing variations in length to be examined. For all of the ejectors tested, an inlet nose radius of 0.75 in. was used, with the exception of the $\mathrm{D}=4.0$ in. ejector which had in inlet nose radius of $0.5 \mathrm{in}$. in order to fit within the shroud. Each ejector inlet was fitted with a flange that sealed it within the shroud, thereby insuring that all air and hot gas passed through the ejector (air could not go around the outside).

It is noted that the dimensions of the ejectors used in this experiment were not selected on the basis of any analysis. They were originally fabricated for the thrust augmentation optimization tests referenced earlier (refs. 9 and 14), but were conveniently available for the present tests. On the unproven, but rational, supposition that high thrust augmentation configurations will yield relatively high pressure gain

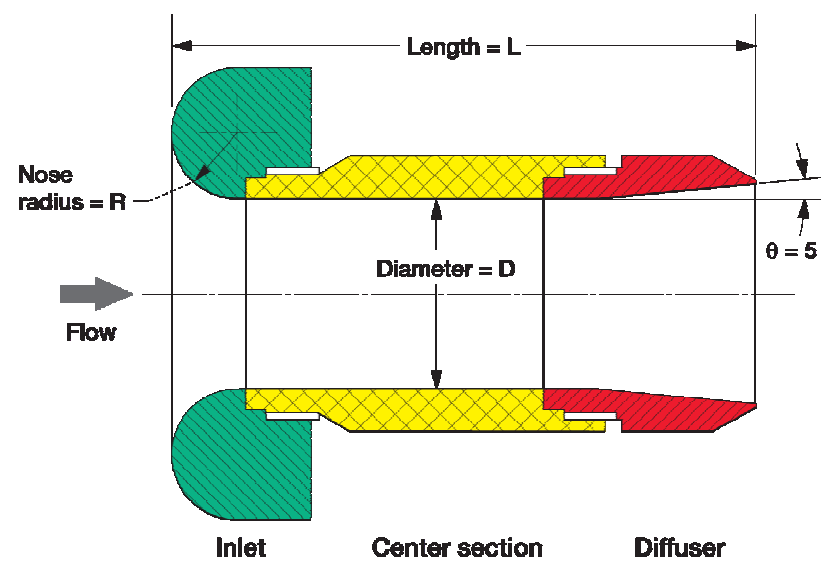

(a)

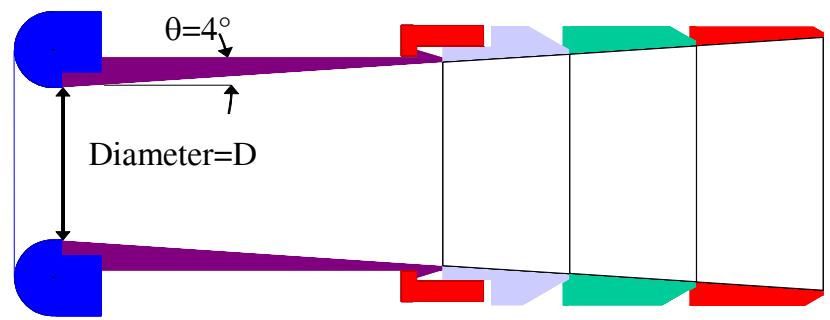

(b)

Figure 4.- Schematics of straight (a), and tapered (b) ejectors used in the experiment. however, they were a logical set to use.

\section{Shroud}

The shroud was constructed from 6.0 in. diameter, schedule 40, stainless steel sections, with standard flanges. This diameter was chosen because it was the smallest within which the existing test ejectors would fit. The assembled unit is shown in figure 5(a). Ideally, it is desirable to make the shroud as small as possible. Doing so results in a more compact, lighter weight, combustor for a given application. Furthermore, a small diameter in the region surrounding the pulsejet driver would result in higher speed bypass flow, which would provide more convective cooling effectiveness for the hottest section. In the present tests, the surface temperature of the pulsejet component exceeded $1700^{\circ} \mathrm{R}$ in some regions. However, acoustic considerations must be made when selecting the shroud diameter. The diameter, or cross sectional profile of the shroud has a clear impact on its acoustic properties and these, in turn, can have a profound effect on the pulsejet performance. In fact, it was found that not only the shroud diameter, but its overall length and the hardware used to terminate each end (a crude diffuser on the inlet and a flat plate at the exhaust) produced an acoustic, or weak wave structure that profoundly affected the pulsejet operation to the point that it would not run, or stopped running shortly after commencing operation. In an attempt to alleviate some of this interaction, a perforated, mild steel liner was installed along the entire length of the shroud, with a standoff distance from the shroud wall of approximately $0.25 \mathrm{in}$. No rigorous selection of hole size or solidity was made in constructing the liner. Conveniently available materials were used. The liner can be seen installed in one of the shroud sections in figure 5(c). Here, several photographs of rig components, as well as the assembled shroud, are shown. The liner proved to be somewhat helpful in that it allowed operation with some configurations that was not otherwise possible. A more thorough design effort would likely have resulted in a much more effective article. 


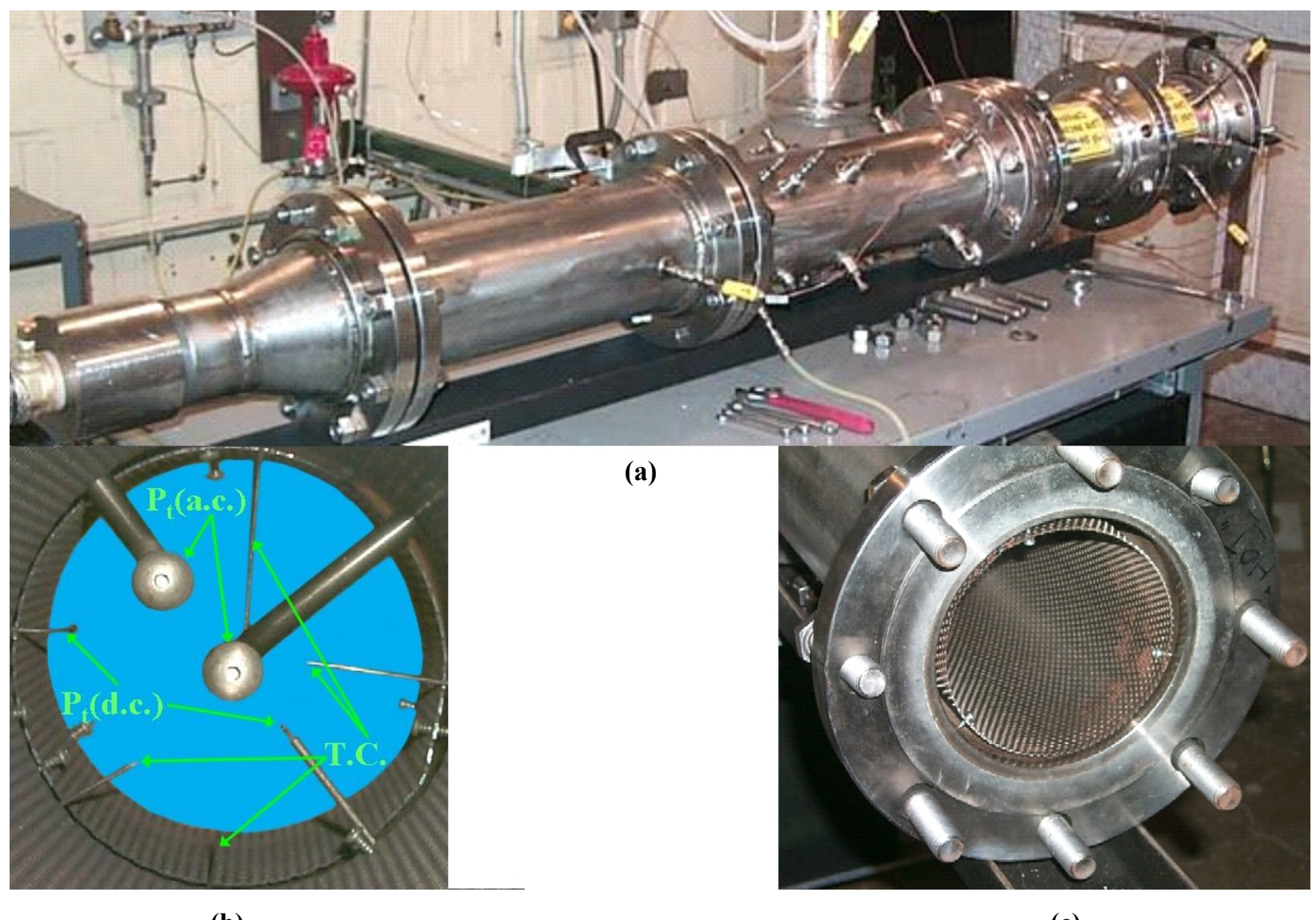

(b)

(c)

Figure 5.-Photographs of the pulsejet-driven, pressure-gain combustor rig: (a) assembled unit, (b) downstream probe arrangement, and (c) view of liner.

\section{Instrumentation}

The primary measures of interest for the experiment were the total pressure and temperature ratios across the rig, and the total pressure fluctuations in the flow downstream of the ejector. The total temperature ratio indicates the amount of chemical energy being added, the total pressure ratio indicates the benefit obtained from the concept (see fig. 1) and the total pressure fluctuation level indicates the degree of unsteadiness in the flowfield aft of the ejector. The pressure ratio was actually calculated from a pressure difference, namely:

$$
\mathrm{PR}=1+\frac{\Delta \mathrm{P}}{\mathrm{P}_{\mathrm{t}}^{\text {upstream }}}
$$

Where $\Delta \mathrm{P}=\mathrm{P}_{\mathrm{t}}^{\text {downstream }}-\mathrm{P}_{\mathrm{t}}^{\text {upstream }}$. The upstream total pressure was measured using a single total pressure probe* located several inches upstream from the pulsejet inlet, and centered in the shroud (refer to fig. 2). The probe was connected to a low frequency transducer via approximately $4 \mathrm{ft}$. of $0.063 \mathrm{in}$. O.D. stainless steel tubing in order to damp any acoustic oscillations. The transducer signal was also filtered using a $10 \mathrm{~Hz}$. low-pass filter, after which it was amplified and time averaged over a 5.0 second period. In a highly unsteady environment, mass-averaged values are more appropriate than time-averaging. As will be seen however, the unsteadiness in this region is relatively small (compared to the pulsejet combustion chamber for example), and time averaging is warranted.

\footnotetext{
* Total pressure probes were constructed by forming an 'L' shaped section of 0.063 in. O.D. (0.031 in. I.D.) stainless steel tubing, and inserting it into a 0.13 in. O.D. sleeve to add rigidity.
} 
The downstream total pressure was measured using a single total pressure probe mounted 1.125 in. radially from the shroud wall. The axial location is shown in figure 2. The radial position can be seen on the left side of figure 5(b). In this figure the probe is labeled $P_{t}($ d.c.). Note that there is another total pressure probe shown in figure 5(b). It is 2.0 in. from the shroud wall. A third probe was also temporarily mounted directly along the centerline. Preliminary tests for flow uniformity were conducted by taking pressure readings from these probes with the pulsejet operational and with a tapered ejector installed. Pressure ratio, as calculated from equation (1) varied by less than 0.1 percent between the three probes. Thus, the use of only one probe was justified. A tubing section of $4 \mathrm{ft}$. length, 0.063 in. O.D. was connected to one side of a low frequency differential pressure transducer. The other side of this transducer was connected to upstream total pressure probe. Like the upstream total transducer, the differential transducer signal was $10 \mathrm{~Hz}$. low-pass

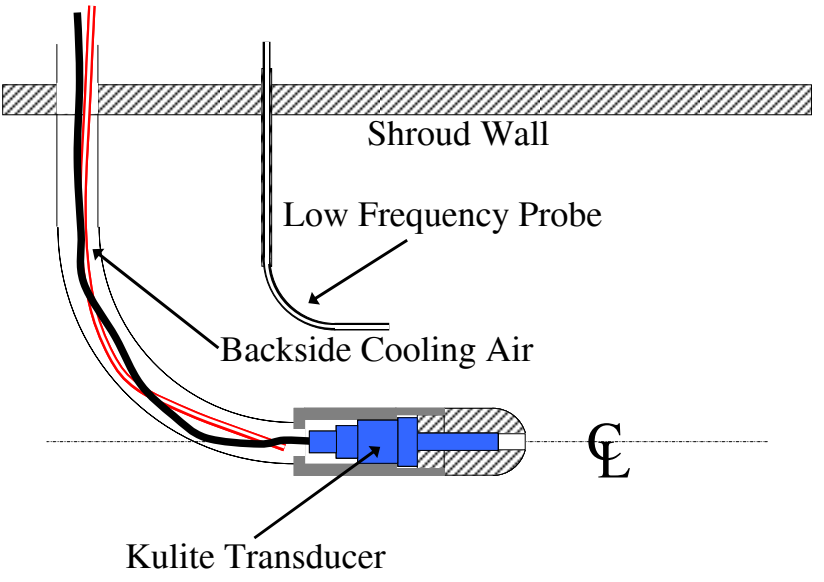

Figure 6.-High frequency pressure transducer installation. filtered, amplified, and averaged over a 5.0 second period.

Total pressure fluctuations (unsteady pressures) were measured using two probes with high frequency Kulite (model\# XTEH-7L) transducers installed directly inside. They can be seen in a head-on view in figure 5(b) where they are labeled as $P_{t}$ (a.c.). A side view of one of the probes is shown in figure 6 . The transducer face is rated to $1210^{\circ} \mathrm{R}$; however, the body is only rated to $985^{\circ} \mathrm{R}$. Thus, a small amount of backside cooling air was required for the probe, and was supplied as shown in the figure. Although the transducer was rated for high temperature, it was designed for operation at a consistent temperature. The nature of the testing in this experiment entailed relatively short duration hot-runs followed by lengthy cool down periods. As such, the transducer experienced large thermal transients and did not operate at any single temperature. This, in turn, led to relatively large shifts in the absolute pressure reading that it supplied. However, the nature of the transducer thermal response is to shift the linear relationship between pressure and output voltage up or down. The slope remains valid. The transducers were therefore a.c. coupled to the acquisition system, where they were used to obtain valid pressure fluctuations readings as deviations from the time-averaged values measured with the low frequency probes.

Upstream total temperature was measured using a single shielded Type-K thermocouple in the same axial position as the upstream total pressure probe. Downstream total temperature was measured using a four-probe arrangement of thermocouples, positioned at different radial locations, and connected in parallel to provide an area averaged reading. The radial positions can be seen in figure 5(c). Axially, the thermocouple probes were positioned just downstream of the downstream total pressure probes, as shown in figure 2. No filtering or time-averaging was applied to the thermocouple signal.

In addition to the overall performance measuring instrumentation just described, instrumentation was also available to measure total air flow rate, time-averaged pulsejet combustion chamber pressure, fuel flow rate, and the pulsejet outer surface temperature. The air flow rate measurement system was a standard, low-loss, venturi-type. The pulsejet chamber pressure, a metric useful for determining the performance of the operational pulsejet independent of the overall system performance, was measured using a low frequency transducer coupled to a $4 \mathrm{ft}$. long, 0.063 in. O.D., stainless steel tubing section, which penetrated the combustion chamber, and was terminated flush with the inside wall (see fig. 3). As with the other transducers of this sort, the signal was low-pass filtered at $10 \mathrm{~Hz}$., and time-averaged over a $0.2 \mathrm{sec}$. interval. Fuel flow rate was measured by taking readings of the fuel tank level before and after each run, multiplying the calibrated volume change by the known density of gasoline, and dividing the result by the test run time. This was often an invalid method of measuring the fuel flow rate because the run time was measured from the moment that the pulsejet commenced self-sustained operation until it was shut down. The measured fuel consumed included that of the run and that used for starting. As mentioned, the pulsejet is started using brief bursts of high pressure air direct at the inlet. These induce both air and fuel into the pulsejet combustion chamber. Multiple bursts are often required for successful starting which results in fuel being consumed before the test time begins. This, in turn leads to average fuel flow rate calculations that are too high. As will be discussed later however, they provide a rough measure of fuel flow which, along with the air flow 
measurements, can be used to determine overall stoichiometry. This can in turn be used to predict downstream temperature and compare with measured values.

\section{E. Test Operation}

Typical test runs were 15 seconds long once resonant operation was established. Resonant operation was detected audibly by the operator. As mentioned, portions of the pulsejet become red-hot during test runs and it was decided that a 15 second time limit would minimize hot, cyclic damage. Furthermore, the reed valves used in the pulsejet have a limited number of cycles before they fail. In an effort to avoid excessive valve replacement, which requires a teardown of the rig, short test times were sought. Test data was acquired during the last 5 seconds of each run.

Subsequent to testing it was found that while 15 seconds is sufficient time to establish steady readings for average pressure, it is not sufficient for the thermocouples. This is seen clearly in figure 7 which shows transducer output of rig pressure difference, $\Delta \mathrm{P}$, and downstream temperature during a run of extended duration. Also shown in the figure are the normal run time window, and the data acquisition time during which time-averages are made and point measurements are obtained. The pressure difference, from which overall pressure ratio is obtained achieves a level profile relatively quickly ${ }^{\dagger}$. The thermocouple readings are still rising during the acquisition time and it appears that the true steady-state temperature is 100 to $150^{\circ} \mathrm{R}$ higher than what was recorded. Analysis later confirmed that this rise-time was consistent with the dimensions of the thermocouple sensing element.

The performance figure of merit for this system is overall pressure ratio as a function of overall temperature ratio. Therefore, errors in temperature measurement will impact results. As a crude correction for the error just described, $100^{\circ} \mathrm{F}$ was added to each of the measured temperature data points to be presented.

\section{Results}

\section{A. Ejector Optimization}

Each of the ejectors described was run in the shrouded rig over range of overall air mass flow rates (and therefore temperature ratios) and the corresponding pressure ratio was measured. The objective was to find the ejector which produced the largest pressure ratio for a given temperature ratio. In the context of this experiment, this will be referred to as an optimization process. For this portion of the testing, the largest of four available spacer sets for the exhaust flow gap setting was used. This produced the lowest shroud pressures for a given flow rate, and the least variation in shroud pressure as mass flow was varied. As will be discussed in subsequent sections, it also allowed for the greatest variation overall temperature ratio due to unexplained operability issues that arose at higher shroud pressures. The results of the tests are shown in figures 8 through 10. Here overall total pressure ratio is

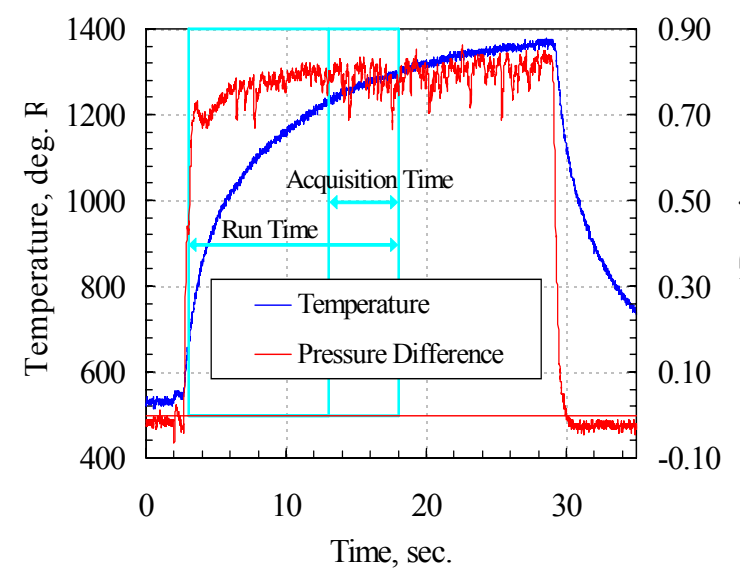

Figure 7.-Traces of rig pressure difference, $\Delta \mathrm{P}$, and downstream temperature during a run of extended duration.

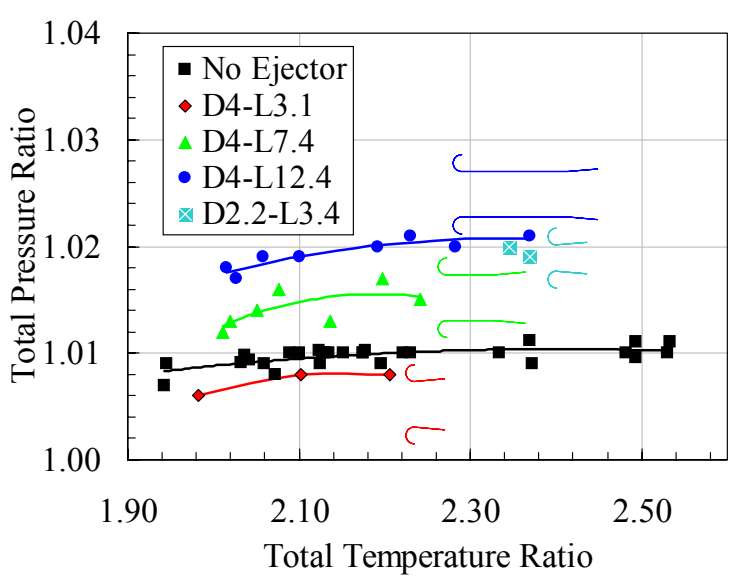

Figure 8.-Total pressure ratio as a function of total temperature ratio for the 4.0 and $2.2 \mathrm{in}$. diameter straight ejectors. The number adjacent to $\mathrm{L}$ in the legend denotes the ejector length in inches.

\footnotetext{
${ }^{\dagger}$ Most runs actually showed a much smoother pressure trace than that of figure 7 during the acquisition period. This trace may indicate the early stages if valve failure.
} 


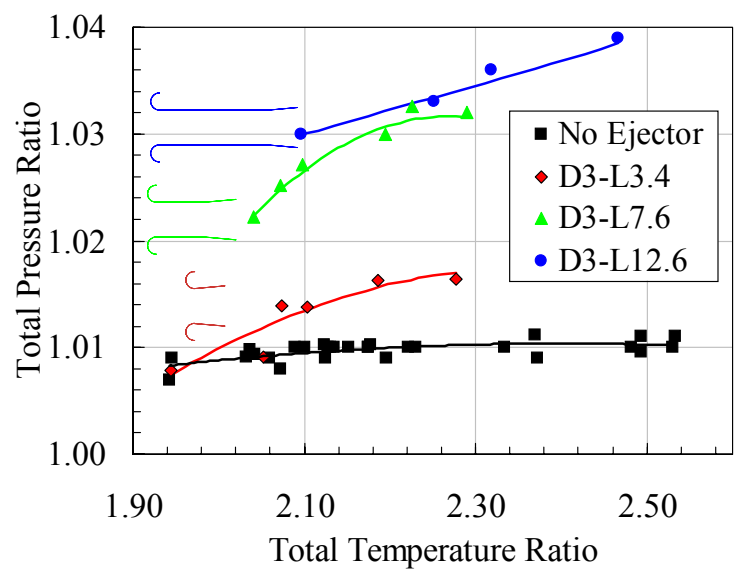

Figure 9.- Total pressure ratio as a function of total temperature ratio for the 3.0 in. diameter straight ejectors. The number adjacent to $\mathrm{L}$ in the legend denotes the ejector length in inches.

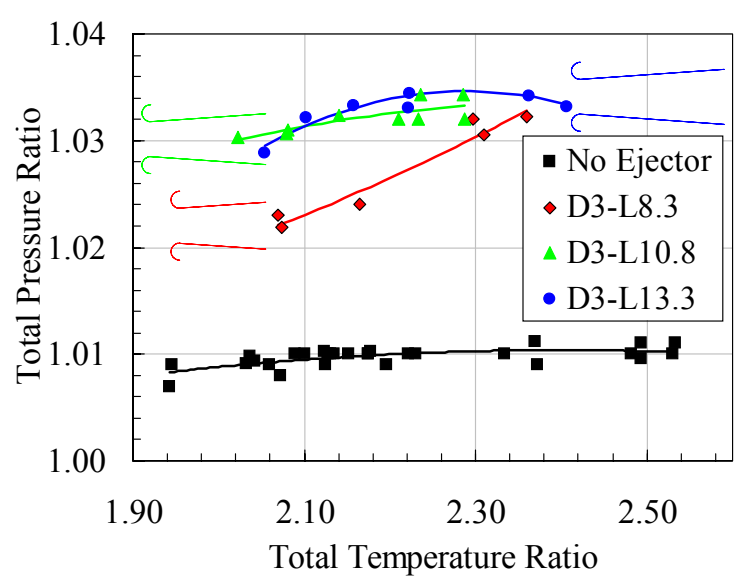

Figure 10.-Total pressure ratio as a function of total temperature ratio for the 3.0 in. diameter tapered ejectors. The number adjacent to $\mathrm{L}$ in the legend denotes the ejector length in inches.

plotted as a function of overall temperature ratio for each of the ejector configurations tested. Ejectors are denoted by a diameter and length specification (in inches) in the plot legend. For each plot the maximum temperature ratio measured was set by thermal limitations of instrumentation. The minimum temperature ratio measured was generally established by a failure of the pulsejet to operate at the required overall flow rate. No results are shown from the longest $(\mathrm{L}=16.8$ in.) straight ejectors because in these configurations the pulsejet would not start. For this same reason only results from the shortest length of the $\mathrm{D}=2.2 \mathrm{in}$. ejectors are shown. The data points from each ejector tested have been, fit with a polynomial. The fit has no physical basis and is made in order to clarify trends.

Examining figures 8 through 10, three conclusions are evident. First, there is a slight pressure gain obtained with no ejector present in the system. This was expected since the shroud itself, with a diameter of 6.0 in., is actually a large ejector, albeit one with poor performance. It is noted that a pressure drop was verified in every configuration when air was forced through the system without the pulsejet operating. Thus, the instrumentation was performing as expected. Second, the presence of an ejector in a pulsejet-driven combustor can improve performance. Third, the level of performance is sensitive to both the diameter and length of the ejector.

The 3.0 in. diameter ejectors (tapered and straight) produced the highest pressure ratio for a given length. This is consistent with thrust augmentation measurements made with the same ejectors and pulsejet driver, and described in reference 9. In that experiment the highest levels of thrust augmentation were also found with a 3.0 in. diameter ejector. That high thrust augmentation and pressure-gain are related is a somewhat intuitive observation; however, it should be kept in mind that in the shrouded configuration of the present experiment, the ejector is not operating as it does in the open air (though the pulsejet is). For the reference 9 thrust augmentation experiment, entrainment ratios ( $\dot{\mathrm{m}}_{\text {ejector }} / \dot{\mathrm{m}}_{\text {pulsejet }}$ ) in excess of 16 were measured. This is flow induced though the ejector by the driver and is directly related to thrust augmentation. In the present experiment, the entrainment ratio cannot be measured directly; however, it can be estimated from the known overall air flow rate and the calculated thrust of the pulsejet (described below). Typical estimated entrainment ratios were less than 5. Hence, the ejector is functioning somewhat 'off design,' but evidently effectively.

In general it was found that for all the ejector diameters tested, the performance improved as the ejector length grew. However, for both the tapered and straight 3.0 in. diameter ejectors the differences in performance between the longest and intermediate length ejectors was much less than between ejectors of intermediate and shortest length. In fact, given the scatter in the data, the performance of the long and intermediate length, straight and tapered, 3.0 in. diameter ejectors can be considered comparable. For unexplained reasons however, starting the pulsejet was easiest when the intermediate length tapered ejector was installed, and thus it was chosen for further testing at higher pressures. Clearly it is a configuration that is representative of the highest performance attained, and will therefore be termed the optimal design. 


\section{B. Pulsejet Performance}

When examining the overall performance of the system as presented in figures 8 through 10 , it is not evident whether changes result from the different ejectors or altered performance of the pulsejet. This can be discerned however, since the pulsejet was equipped with a low frequency static pressure sensor mounted on the combustion chamber. It was found in previous studies (ref. 9) that the difference between the time-averaged combustion chamber pressure, $\mathrm{p}_{\mathrm{cc}}$ and the upstream or ambient pressure correlated well with the thrust according to the relation

$$
\overline{\mathrm{F}}=\mathrm{A}_{\text {exit }}\left(\mathrm{p}_{\mathrm{cc}}-\mathrm{P}_{\text {upstream }}\right)
$$

where $A_{\text {exit }}$ is the pulsejet tailpipe area. This relation assumes that the shroud Mach number is very low and that the pulsejet exit pressure is essentially the same as the upstream pressure. If the upstream pressure (and therefore density) in the shroud for all of the test points were constant, then equation (2) could be used directly to measure whether the pulsejet performance was changing, and thus isolate the mechanism responsible for the changes in overall pressure ratio seen in figures 8 through 10. As mentioned however, the overall temperature ratio is controlled by the overall air mass flow rate which, for a given fixed exhaust gap spacing, also alters the upstream pressure. Figure 11 illustrates this pressure variation with mass flow for each of the four exhaust gap spacers used. The optimization testing was performed with the largest exhaust spacing which, from figure 11, and the known near constant upstream temperature of $520^{\circ} \mathrm{R}$, indicates upstream density variations of nearly 40 percent. For the subsonic pulsejet flow the thrust can also be written as

$$
\overline{\mathrm{F}} \approx \rho_{\text {upstream }} \frac{\mathrm{A}_{\text {exit }}}{\mathrm{g}_{\mathrm{c}} \mathrm{TR}_{\mathrm{PJ}}}\left(\overline{\mathrm{u}}^{2}-\overline{\mathrm{u}^{\prime 2}}\right)
$$

where $\rho_{\text {upstream }}$ is the upstream density, $g_{\mathrm{c}}$ is the Newton constant, $\mathrm{TR}_{\mathrm{PJ}}$ is the pulsejet (not the overall) total temperature ratio, and $\overline{\mathrm{u}}^{2}$ and $\overline{\mathrm{u}^{\prime 2}}$ are the square averages of the mean and periodically fluctuating velocity components at the pulsejet exit plane. Thus, according to equation (3), the thrust of the pulsejet should change at different test points simply because the density is changing. In other words, the pulsejet thrust is increasing because more flow is passing through it.

With this in mind, the thrust per unit area $\left(\overline{\mathrm{F}} / \mathrm{A}_{\text {exit }}\right)$ is shown in figure 12 for all of the test points, both with and without ejectors present, as a function of upstream density. There is substantial scatter in the data, which is typical of pulsejet operation; however; it is apparent that a nearly linear trend exists. Each of the data sets (with and without ejectors present) has been fit with a linear regression, which is also shown. The dashed line in the figure is a linear regression fit of the combined data sets. The ejector optimization was performed with the largest exhaust gap spacing and it is evident that in this region of figure 12 (the lower left sector outlined in green) no substantial differences exist in the pulsejet performance with or without ejectors. Hence, the overall performance enhancements

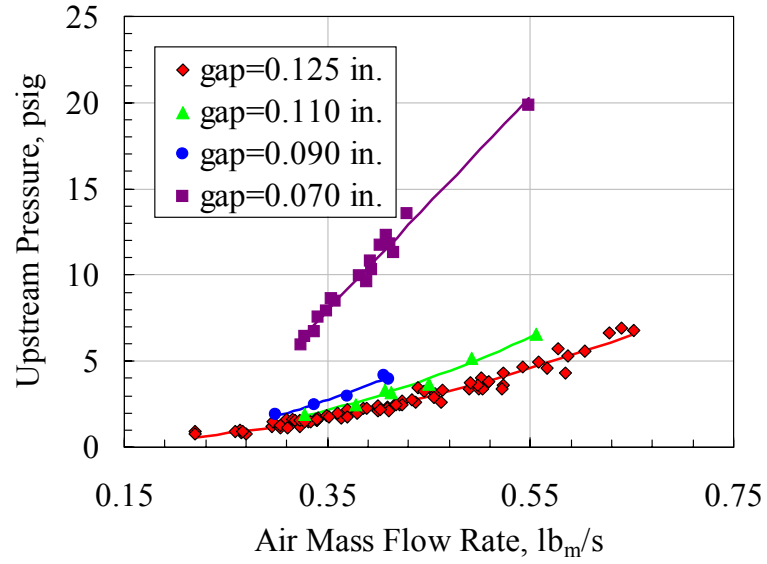

Figure 11.-Upstream total pressure ratio as a function of air mass flow rate for the four exhaust gap spacers used.

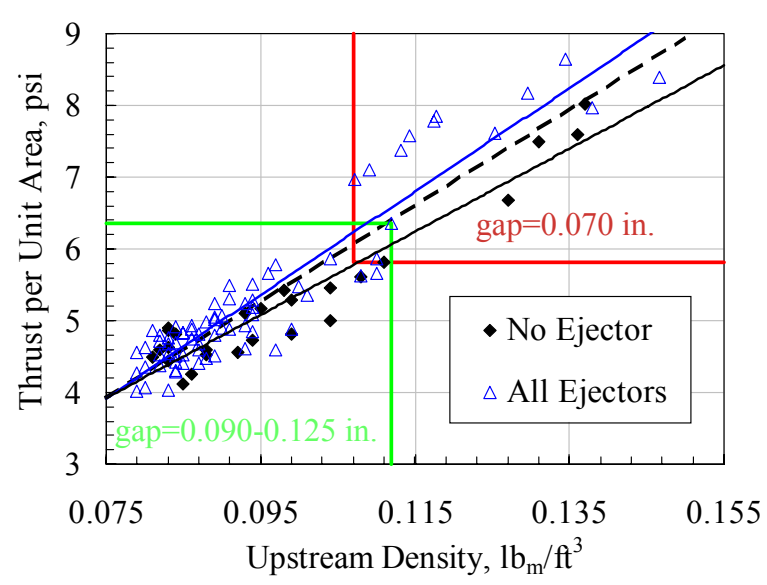

Figure 12.- Thrust per unit area for all of the test points, with and without ejectors present, as a function of upstream density. 
seen in figures 8 through 10 are due to the ejectors, not the pulsejet itself. There is a more substantial difference between pulsejet performance with and without the ejector at the highest upstream densities when the smallest exhaust gap was used. The reason for this difference is unclear at the time; however, it is a maximum 10 percent discrepancy as assessed by the respective regression fits, which is acceptable. It is interesting to note as an aside that the overall temperature ratios shown in figures 8 through 10 decrease as the overall air flow rates, and hence upstream densities increase. But from figure 12, the pulsejet thrust increases with upstream density. Since overall pressure ratio generally decreases with decreasing temperature ratio in figures 8 through 10, it may be inferred that the lowest overall pressure ratios are attained when the highest thrust is being delivered from the pulsejets. Evidently, the additional thrust, or pumping energy is negated by the increased bypass flow which must be pumped.

\section{Higher Pressure Testing of Optimal Ejector}

Each of the three remaining exhaust gap spacer sets was installed in the rig and with each one the pulsejet was operated over a range of overall flow rates, both with and without the optimal ejector in place. The results are shown in figure 13. As in figures 8 through 10, overall pressure ratio is shown as a function of overall temperature ratio. The smaller the exhaust gap used, the higher the shroud pressure maintained for a given overall air flow rate. Smaller gaps also led to larger variations in shroud pressure for a given change in air mass flow rate, as seen in figure 11. Thus, as overall temperature ratio was changed by varying air mass flow, the upstream or shroud pressure was also changing for any exhaust gap spacer used. The trend of figure 13 demonstrates that the performance of the rig was not strongly affected by the upstream pressure and density variations. For a given temperature ratio achieved, the overall pressure ratio was the same regardless of the upstream pressure. It is noted however that there was a general rightward shift toward higher temperature ratios as the upstream pressure was raised. This may be explained as follows.

The measured temperature rise across the rig for all of the test points is shown in figure 14 as a function of measured overall air fuel ratio. Also shown is the expected result as calculated for a $\mathrm{C}_{6} \mathrm{H}_{10}$ (a gasoline-like hydrocarbon)/air mixture using the STANJAN thermodynamic package (ref. 15). The measurement of fuel consumption was, as mentioned, crude and error prone, as evidenced by the broad scatter in the data. Nevertheless, it is clear from figure 14 that, on an overall basis, significantly less heat release is occurring than expected. The proposed (though not provable) reason for this is that the actual process taking place is a very rich reaction in the pulsejet followed by rapid mixing with the bypass flow. The mixed flow is sufficiently cool such that all further reaction, or heat release, virtually ceases. This process would give the appearance of the reduced fuel heating value seen in figure 14. It would also result in an exhaust flow filled with unburnt hydrocarbons. No measurements of such were taken during testing, but the odor that is characteristic of such flows was present in the test facility after each run, which tends to confirm the proposed process. Furthermore, it is well documented that pulsejets such as the one used in the present experiment do, indeed, run rich. Stoichiometric combustion yields higher exhaust temperatures than does rich combustion. Thus, if operation of the rig at higher upstream pressure led to leaner (more

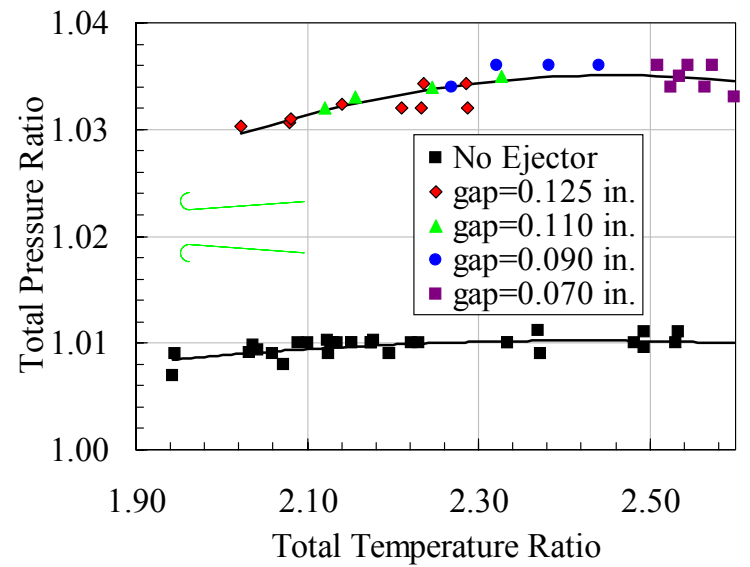

Figure 13.-Total pressure ratio as a function of total temperature ratio for the 3.0 in. diameter, 10.8 in. long tapered ejector, with elevated upstream pressure (reduced exhaust gap spacing).

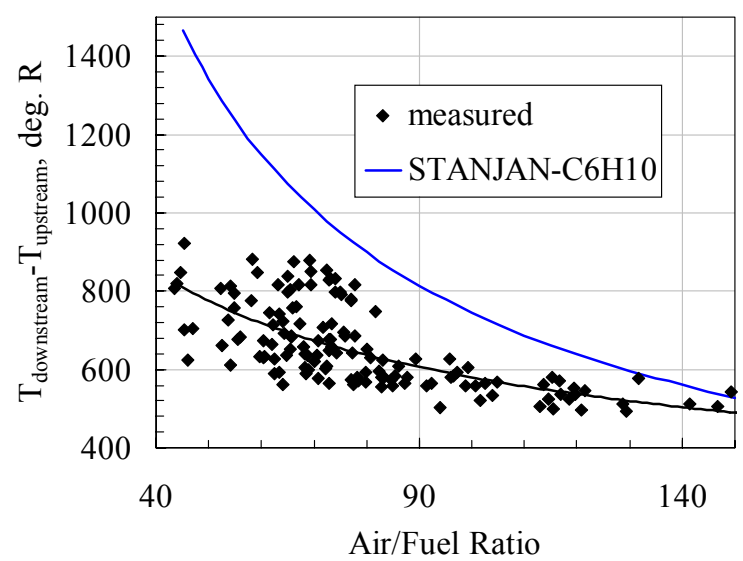

Figure 14.-Measured temperature rise due to combustion as a function of air/fuel ratio. Calculations from STANJAN code for $\mathrm{C}_{6} \mathrm{H}_{10}$ fuel and air are also shown. 
stoichiometric) operation of the pulsejet, then when this hotter flow mixed with the bypass flow the resulting downstream temperature would be higher as seen in figure 13. It has already been shown in figure 12 that the increase in pulsejet thrust at higher upstream pressures is linearly related to increased air mass flow through the device if the increased air mass flow is due to higher density, not higher velocity. This is proposed here. Recalling from figure 3 that the fuel delivery system is a venturi-type, it can be deduced from Bernoulli's equation that the pressure differential which drives a venturi flow is linearly related to the density of the incoming air. However, the flow rate of fuel through the regulating jet of the fuel system is related to the square root of the venturi pressure differential. In other words, as the upstream density increases, both the air and fuel flow through the pulsejet increase; however, the air flow rate increases more than the fuel flow rate. Hence, the pulsejet operates leaner, emits a hotter flow, and causes the overall temperature ratio in the rig to increase as seen in figure 13 .

\section{Unsteadiness Measurements}

Unsteady pressure fluctuations downstream of the ejector were obtained for all runs using the two high frequency probes described earlier. As described earlier, these transducers measured deviations in pressure from the mean value. Fluctuation levels were recorded as root mean square (rms) pressure readings, averaged over a 5.0 second interval. The rms readings from the two probes were then averaged to provide a single measure of unsteadiness (the two readings differed from one another by less than 0.7 percent). These measurements are presented in figure 15. The rms pressure fluctuations have been normalized by the time-averaged downstream total pressure, and are plotted as a function of overall temperature ratio. Data for all upstream pressures (exhaust gap settings) are shown. Also shown in the figure is the baseline rms level obtained when there was no flow in the rig. This represents electrical or background noise. For configurations both with and without the so-called optimal, tapered, 3.0 in. diameter, $10.8 \mathrm{in}$. long ejector, the rms pressure appears to stay at approximately 4.5 percent of the mean value regardless of

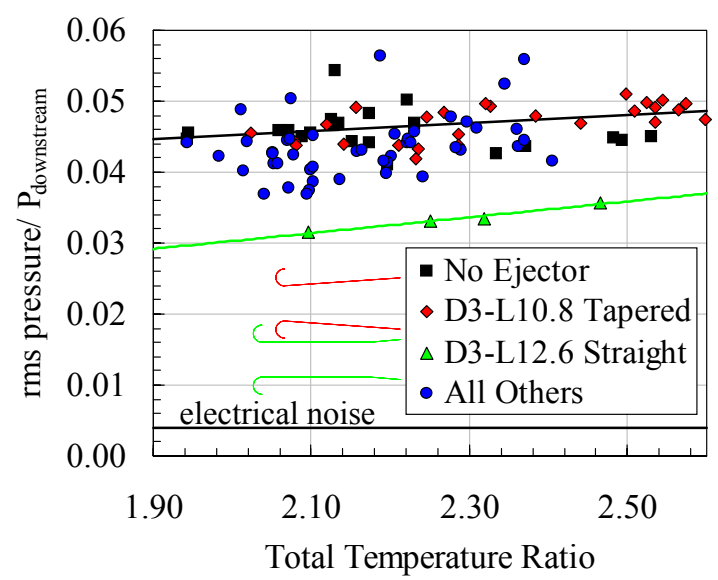

Figure 15.-Measured normalized rms total pressure fluctuation downstream of the ejector as a function of overall temperature ratio for all runs.

the temperature ratio or upstream pressure. That is to say, the presence of the ejector doesn't seem to mitigate or worsen the unsteadiness compared to having no ejector at all. For reasons that are not clear however, the straight 3.0 in. diameter, 12.6 long ejector does show a reduction in unsteadiness to a level of approximately 3.2 percent of the mean. Given that the pressure gain performance of this ejector was comparable to the tapered ejector, it may be the better candidate for the label of optimal. Of the two however, it was still the more difficult with which to start the pulsejet. Fluctuation data from all of the other ejectors tested is also shown in figure 15. Some of this data shows levels somewhat below the 4.5 percent average of the optimal ejector; however, the pressure gain performance of these ejectors was too low for the reduced fluctuation results to be worthwhile.

The worst of the fluctuations shown in figure 15 is, of course, well below the level seen in the pulsejet combustion chamber. While such measurements were not available in this experiment, they have been made previously (ref. 9). Typical normalized rms levels are 0.36 , or nearly an order of magnitude above those seen in the shroud. Thus, the use of a shrouded ejector is an effective means for damping pulsations from unsteady combustion. Whether the pressure fluctuation levels seen in the shroud are compatible with efficient operation of a downstream turbine is an open question. However, those presented here suggests that an answer in the affirmative is at least plausible.

It is worth noting that in a previous open-air pulsejet driven ejector experiment, the time-dependant velocity field near the exit of the ejector and at the exit of the pulsejet was mapped using digital particle imaging velocimetry (DPIV). The pulsejet was the same one used in this experiment. The ejector was not performance optimized, having a 2.5 in. diameter, and only a 7 in. length. It was found that the standard deviation of the centerline velocity near the ejector exit was 33 percent of the mean velocity. At the exit plane of the pulsejet, the standard deviation of the centerline velocity was 136 percent. Thus, it appears that both velocity and pressure fluctuations may be substantially mitigated by the use of a shrouded, pulsejet-driven ejector system. 
The power spectra from the high frequency total pressure transducers in the rig provide some insight into the content of the fluctuations. Figure 16 shows results from 1.0 second traces of the highest pressure configuration with and without the optimal ejector present. The data was sampled at $10 \mathrm{kHz}$. The quantities plotted represent the contribution to the signal, in terms of amplitude (not power) at a given frequency. The amplitudes have been normalized by the mean pressure. While the dominant frequency in both cases corresponds to the operational frequency of the pulsejet, there are significant contributions at other frequencies as well. This distribution is interesting as it differs markedly from that of the pulsejet itself. Figure 17 shows the normalized power spectra from a transducer mounted on the combustion chamber wall during previous open air testing (ref. 9). Here, the operational frequency completely dominates, and the relatively strong $900 \mathrm{~Hz}$. signal seen in figure 16 is virtually non-existent. It is believed that the differences in frequency distributions between the two figures are the result of interactions with the shroud. The fact that the shroud fluctuations are not a "pure tone," but are instead composed of multiple frequencies may be beneficial in terms of their impact on downstream turbomachinery performance in any practical application of this type of combustor.

\section{Discussion}

From the results presented thus far, it is clear that a pulsejet-driven, ejector-based, pressure-gain combustor does, in fact, work. That is, it provides a pressure rise, which is a thermodynamic benefit to a gas turbine engine cycle.

\section{A. Issues}

Many issues remain before such a device can be implemented however, and it is worthwhile to note some of them. They include:

1.Cooling.-The pulsejet in this paper measured a surface temperature of nearly $2000{ }^{\circ} \mathrm{R}$ during operation. While the stresses are relatively low, this is an extremely hot, life limiting temperature that will only rise when the combustor faces the elevated discharge temperatures of an upstream compressor. It is possible that equipping the pulsejet with external fins and using a smaller shroud will allow the entrained bypass air to more effectively cool the walls. Of course, this will come at a performance penalty; as such cooling will carry with it a pressure drop for the bypass air.

2.Turbine Cooling.-Any pressure rise device causes difficulties in this area because turbine cooling flows can no longer be supplied by the upstream compressor. Thus, the pulsejet itself must somehow supply the cooling air, or a small boost compressor must be installed. The latter option is extremely unlikely.

3.Integration.-A combustor such as the one presented in this paper is volumetrically large, as well as long compared to its conventional counterpart.

4. Valves.-The pulsejet used in this experiment operates with simple reed valves constructed from spring steel. These tend to fail often, and even more so at high pressure. Of course, the valve design is very crude, having undergone few, if any modifications since the 1950's. It may be possible to extend life considerably using improved materials or design. It may also be possible to use valveless pulsejets, as was done by Kentfield in Ref. 5.

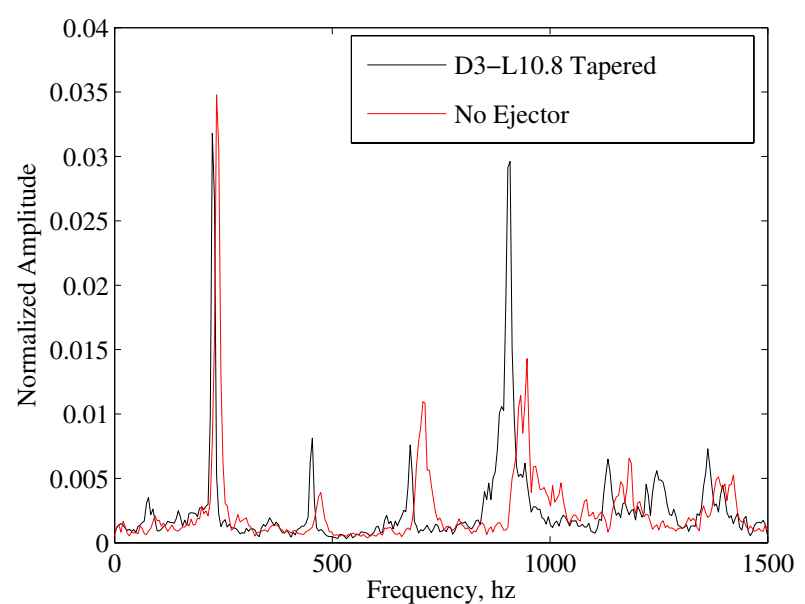

Figure 16.-Normalized power spectra obtained from high frequency pressure transducers with and without the optimal ejector present.

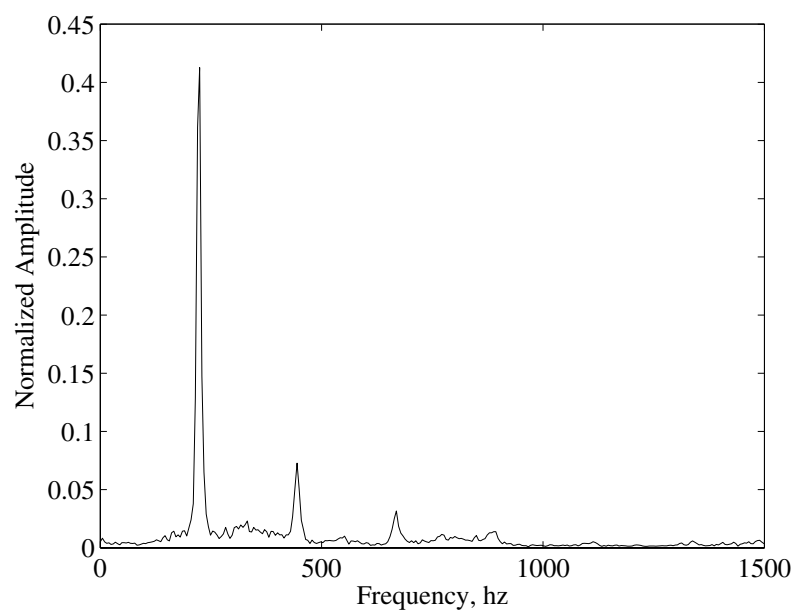

Figure 17.-Normalized power spectra obtained from a high frequency wall-mounted pressure transducer on the combustion chamber of the pulsejet during open air testing. 
This somewhat daunting, and incomplete list should not be interpreted as a roadblock to the technology. The first three of the four items listed are common to nearly all conceivable pressure-gain systems (e.g., wave rotor, detonative combustion, etc.). Any efficiency enhancing concept comes with practical hurdles which must be identified, assessed in terms of risk, and overcome if the payoff is deemed worthy. The current concept is no exception. Furthermore, it is worthwhile noting that the combustion portion of a Brayton (gas turbine) cycle produces far more entropy than the compression of expansion portions. As such, the largest payoffs in terms of cycle efficiency gains are likely to come from concepts which reduce combustion induced entropy production such as the pulsed combustion concept introduced here and elsewhere(refs. 3 to 6 ).

\section{B. Low Emissions}

Pulsejets tend to operate rich, as mentioned. It is not clear whether this is an inherent necessity to their proper operation, or whether it results from poor control of the metered fuel. However, in the present combustor embodiment, it may be possible to use this operational characteristic to some advantage. The ejector which follows the pulsejet has the ability to rapidly mix the bypass flow with the pulsejet discharge. This may be inferred from the fact that good ejector performance relies on a high level of mixedness. This is how momentum is transferred from primary to secondary flow. As pointed out earlier, pulsejet driven ejectors have exceptional performance in terms of thrust augmentation, and do so with relatively short ejectors. Thus, there must be substantial mixing in a relatively short distance, implying that it takes place quite fast. This process may be seen to some degree in figure 18 which shows results from the reference 10 DPIV experiment using an open-air pulsejet and a transparent ejector. Figure 18(a) shows contours of vorticity downstream of the pulsejet and in the ejector just after the characteristic vortex ring has formed. The color spectrum is such that yellow indicates large positive (counterclockwise) vorticity and blue/black represents large negative vorticity (clockwise). Red indicates no vorticity. Note that the secondary flow is irrotational and cannot become rotational except by mixing with the flow from the pulsejet. The volume of the vortex ring corresponds closely to the volume of gas that has discharged from the pulsejet as measured by integrating the near-exit plane velocity profile. Thus, little mixing has taken place. The vortex travels quickly downstream and appears to disintegrate once inside the ejector. In that time however, much entrainment and mixing takes place. Figure 18(b) shows vorticity contours on the same scale, approximately $1.0 \mathrm{msec}$ later. This point was chosen since it is the moment when the ejector becomes completely filled with rotational fluid. The volume of rotational fluid in figure 18 (b) is approximately 2.3 times the volume discharged from the pulsejet by this time. Thus, in the span of $1.0 \mathrm{msec}$. the ejector has become filled with a mixture of pulsejet effluent and entrained air.

With this sort of rapid mixing, it is possible that the configuration presented in this paper is a manifestation of a practical Rich-burn/Quench/Lean-burn (RQL) combustor (ref. 17). The RQL concept is intended to reduce $\mathrm{NO}_{\mathrm{x}}$ emissions by minimizing the time at nearstoichiometric conditions where the rate of $\mathrm{NO}_{\mathrm{x}}$ production is the greatest. Instead it relies on a sequence whereby a low $\mathrm{NO}_{\mathrm{x}}$ producing, rich combustion process releases some heat, and produces unburnt hydrocarbons. The flow is quenched, or rapidly mixed with air, and completes the reaction of, and heat release from, the unburnt hydrocarbons via a lean process which also produces little $\mathrm{NO}_{\mathrm{x}}$. Of key importance in this sequence is rapid mixing. In steady RQL combustors this is achieved through techniques such as cross-flow injection of the quenching air. Rapid mixing in the present system is affected by the vortex emitted from the pulsejet and possibly the highly turbulent, intermittent jet that follows it. The notion could not be tested in the current experiment, because the bypass air was unheated. As a result, the rapid mixing which did occur resulted in a lean mixture that was so cool as to render the reaction rate, which is exponentially related to temperature, essentially

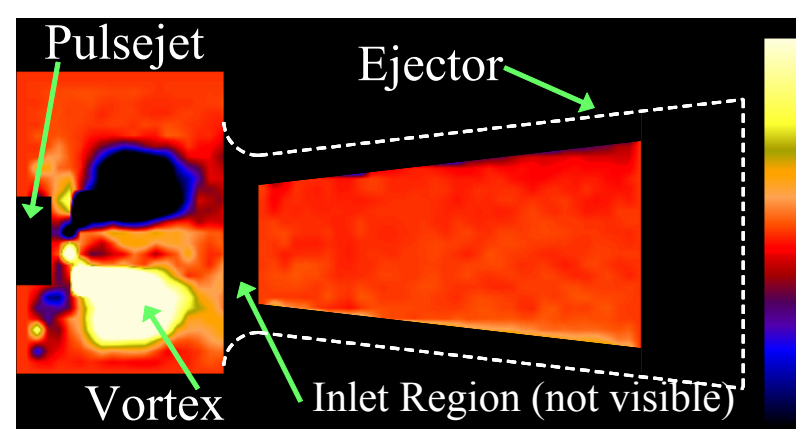

(a)

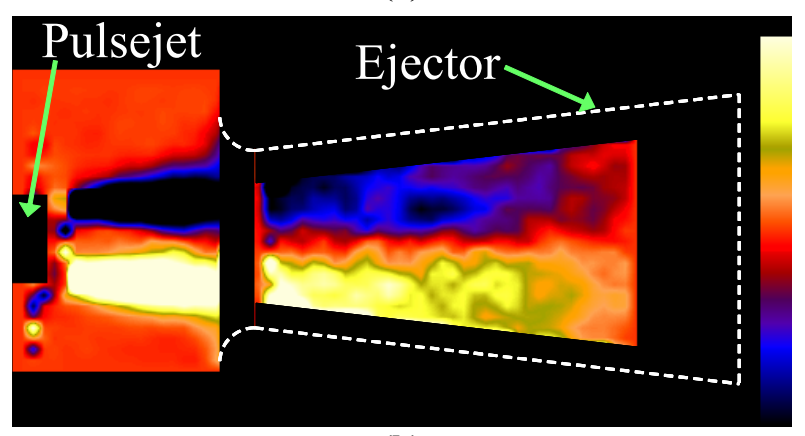

(b)

Figure 18.-DPIV measured contours of vorticity in a pulsejet-driven ejector flowfield at two different times in the cycle, (a) $t=0.0$ msec., (b) $t=1.0$ msec. Data is from reference 10 . 
zero. With the current emphasis on low emissions aircraft, this feature of the pressure-gain combustion system, if realizable, may be of greater value than the increased efficiency afforded by the pressure-gain itself.

\section{Conclusion}

A laboratory rig demonstration of a pulsejet-driven, ejector-based, pressure-gain combustion system was presented. It was shown that at temperature ratios comparable to those of modern gas turbine combustors, pressure ratios near 1.035 were obtained. These pressure ratios, in comparison to those of conventional combustors, may provide a 2 to 3.5 percent reduction in specific fuel consumption when used in a gas turbine engine. It was also shown that the resulting unsteadiness levels, when measured in terms of rms pressure fluctuations, were only about 4.5 percent of the mean total pressure. Such levels are near the acceptability limit in terms of reducing downstream turbine performance. Finally, it was shown that the concept may yield a low emissions combustor by affecting a practical, low loss, Rich-burn/Quench/Lean-burn sequence.

\section{Appendix: Baseline Engine Information for Figure 1}

The following tabulated parameters constitute the baseline turbojet and turbofan engine data used in the cycledeck described to generate the graph shown in figure 1.

\begin{tabular}{|c|c|c|}
\hline Parameter & Turbofan & Turbojet \\
\hline Overall Pressure Ratio (OPR) & 30.00 & 8.00 \\
\hline High Pressure Compressor Ratio & 7.36 & 8.00 \\
\hline Low Pressure Compressor Ratio & 2.50 & 1.00 \\
\hline Fan Pressure Ratio & 1.63 & ---- \\
\hline Fan bypass Ratio & 6.0 & ---- \\
\hline Compressor Efficiency & 0.90 & 0.90 \\
\hline Turbine Efficiency & 0.90 & 0.90 \\
\hline Fan Efficiency & 0.90 & 0.90 \\
\hline Flight Mach Number & 0.80 & 0.80 \\
\hline Ambient Temperature $\left({ }^{\circ} \mathrm{R}\right)$ & 410 & 410 \\
\hline Combustor Exit Temperature $\left({ }^{\circ} \mathrm{R}\right)$ & 2968 & 2400 \\
\hline Cooling Flow (fraction of core) & 0.21 & 0.00 \\
\hline Chargeable Cooling fraction & 0.40 & ---- \\
\hline Ratio of Specific Heats & 1.35 & 1.35 \\
\hline Real Gas Constant $\left(\mathrm{ft}-\mathrm{lb}_{\mathrm{f}} / \mathrm{lb}_{\mathrm{m}} / \mathrm{R}\right)$ & 53.57 & 53.57 \\
\hline Burner Pressure Ratio & 0.95 & 0.95 \\
\hline Fuel Heating Value $\left(B T U / \mathrm{lb}_{\mathrm{m}}\right)$ & 18400 & 18400 \\
\hline Specific Thrust $\left(\mathrm{lb}_{\mathrm{f}}-\mathrm{s} / \mathrm{lb} \mathrm{b}_{\mathrm{m}}\right)$ & 18.26 & 75.86 \\
\hline Specific Fuel Consumption $\left(\mathrm{lb}_{\mathrm{m}} / \mathrm{hr} / \mathrm{lb}_{\mathrm{f}}\right)$ & 0.585 & 1.109 \\
\hline
\end{tabular}

\section{References}

1. Lefebvre, Arthur, H., Gas Turbine Combustion, Taylor and Francis, 1999, Chapt. 4.

2. Oates, Gordon, C. "Aerothermodynamics of Gas Turbines and Rocket Propulsion," American Institute of Aeronautics and Astronautics, 1997.

3. Catchpole, B.G., and Runacres, A., "Constant Volume Gas Turbine Experiments with Gaseous Fuel in a Rotating Pocket Combustor," Mechanical Engineering Note 353, Australian Defense Scientific Service Aeronautical Research Laboratories, October, 1974. 
4. Mathur, Atul, "A Brief Review of the G.E. Wave Engine Program," Proceedings of the 1985 ONR/NAVAIR Wave Rotor Research and Technology Workshop, May 1985.

5. Kentfield, J.A.C., and O'Blenes, M.J., "Small Gas Turbine Using a Second-Generation Pulse Combustor," AIAA Journal of Propulsion, vol. 6 no. 2, 1990, pp. 214-220.

6. Gemmen, R.S., et. al., "Achieving Improved Cycle Efficiency Via Pressure Gain Combustors," ASME 95-GT63, June 1995.

7. Snyder, P.H., Alparslan, B., Nalim, M.R., "Gas Dynamic Analysis of The CVC, A Novel Detonation Cycle," AIAA paper 2002-4069, July 2002.

8. Paxson, D.E., Perkins, H.D., "Thermal Load Considerations for Detonative Combustion-Based Gas Turbine Engines," AIAA-2004-3396, July 2004.

9. Paxson, D.E., Wilson, J., and Dougherty, K.T., "Unsteady Ejector Performance: An Experimental Investigation Using a Pulsejet Driver," AIAA paper 2002-3915, July 2002.

10. John, W.T., Paxson, D.E., Wernet, M.P., "Conditionally Sampled Pulsejet Driven Ejector Flow Field Using DPIV," AIAA paper 2002-3231, June 2002.

11. Lockwood, R.M. "Interim Summary Report on Investigation of the Process of Energy Transfer from an Intermittent Jet to Secondary Fluid in an Ejector-Type Thrust Augmenter," Hiller Aircraft Report No. ARD286, March 1961.

12. Paxson, D.E., "2003 Pulse Detonation Engine Project: University/Government Spring Ejector Meeting," unpublished presentation, 2003.

13. Litke, P.J., Schauer, F.R., Paxson, D.E., Bradley, R.P., and Hoke J.L., "Assessment of the Performance of a Pulsejet and Comparison with a Pulsed-Detonation Engine," AIAA paper 2005-0228, January 2005.

14. Wilson, J, Paxson, D.E., "Unsteady Ejector Performance: An Experimental Investigation Using a Resonance Tube Driver," AIAA paper 2002-3632, July 2002.

15. M.W. Chase Jr., C.A. Davies, J.R. Davies, Jr., D.J. Fulrip, R.A. McDonald, and A.N. Syverud, JANAF Thermochemical Tables, 3rd edition, Journal of Physical and Chemical Reference Data, vol. 14, Supplement 1, 1985.

16. John, W.T., Paxson, D.E., and Wernet, M.P., "Conditionally Sampled Pulsejet Driven Ejector Flow Field Using DPIV," AIAA paper 2002-3231, June 2002.

17. Rizk, N.K.; Mongia, H.C., "Low $\mathrm{NO}_{\mathrm{x}}$ Rich-Lean Combustion Concept Application," AIAA paper 91-1962, June 1991. 
Public reporting burden for this collection of information is estimated to average 1 hour per response, including the time for reviewing instructions, searching existing data sources, gathering and maintaining the data needed, and completing and reviewing the collection of information. Send comments regarding this burden estimate or any other aspect of this collection of information, including suggestions for reducing this burden, to Washington Headquarters Services, Directorate for Information Operations and Reports, 1215 Jefferson Davis Highway, Suite 1204, Arlington, VA 22202-4302, and to the Office of Management and Budget, Paperwork Reduction Project (0704-0188), Washington, DC 20503.

\begin{tabular}{|l|l|l|}
\hline 1. AGENCY USE ONLY (Leave blank) & $\begin{array}{c}\text { 2. REPORT DATE } \\
\text { August } 2005\end{array}$ & $\begin{array}{r}\text { 3. REPORT TYPE AND DATES COVERED } \\
\text { Technical Memorandum }\end{array}$ \\
\hline
\end{tabular}

\section{TITLE AND SUBTITLE}

5. FUNDING NUMBERS

Ejector Enhanced Pulsejet Based Pressure Gain Combustors: An Old Idea With a New Twist

6. AUTHOR(S)

Daniel E. Paxson and Kevin T. Dougherty

WBS-22-066-10-05

\section{PERFORMING ORGANIZATION NAME(S) AND ADDRESS(ES)}

National Aeronautics and Space Administration

John H. Glenn Research Center at Lewis Field

Cleveland, Ohio 44135-3191

8. PERFORMING ORGANIZATION REPORT NUMBER

E-15224

9. SPONSORING/MONITORING AGENCY NAME(S) AND ADDRESS(ES)

National Aeronautics and Space Administration

Washington, DC 20546-0001

10. SPONSORING/MONITORING AGENCY REPORT NUMBER

NASA TM-2005-213854

AIAA-2005-4216

11. SUPPLEMENTARY NOTES

Prepared for the 41st Joint Propulsion Conference and Exhibit cosponsored by the AIAA, ASME, SAE, and ASEE, Tucson, Arizona, July 10-13, 2005. Daniel E. Paxson, NASA Glenn Research Center; and Kevin T. Dougherty, QSS Group, Inc., 21000 Brookpark Road, Cleveland, Ohio 44135. Responsible person, Daniel E. Paxson, organization code RIC, 216-433-8334.

12a. DISTRIBUTION/AVAILABILITY STATEMENT 12b. DISTRIBUTION CODE

Unclassified - Unlimited

Subject Category: 07

Available electronically at http://gltrs.grc.nasa.gov

This publication is available from the NASA Center for AeroSpace Information, 301-621-0390.

13. ABSTRACT (Maximum 200 words)

An experimental investigation of pressure-gain combustion for gas turbine application is described. The test article consists of an offthe-shelf valved pulsejet, and an optimized ejector, both housed within a shroud. The combination forms an effective 'can' combustor across which there is a modest total pressure rise rather than the usual loss found in conventional combustors. Although the concept of using a pulsejet to affect semi-constant volume (i.e., pressure-gain) combustion is not new, that of combining it with a well designed ejector to efficiently mix the bypass flow is. The result is a device which to date has demonstrated an overall pressure rise of approximately 3.5 percent at an overall temperature ratio commensurate with modern gas turbines. This pressure ratio is substantially higher than what has been previously reported in pulsejet-based combustion experiments. Flow non-uniformities in the downstream portion of the device are also shown to be substantially reduced compared to those within the pulsejet itself. The standard deviation of total pressure fluctuations, measured just downstream of the ejector was only 5.0 percent of the mean. This smoothing aspect of the device is critical to turbomachinery applications since turbine performance is, in general, negatively affected by flow non-uniformities and unsteadiness. The experimental rig will be described and details of the performance measurements will be presented. Analyses showing the thermodynamic benefits from this level of pressure-gain performance in a gas turbine will also be assessed for several engine types. Issues regarding practical development of such a device are discussed, as are potential emissions reductions resulting from the rich burning nature of the pulsejet and the rapid mixing (quenching) associated with unsteady ejectors.

14. SUBJECT TERMS

Pulse detonation engines; Combustion; Thermodynamic cycles

\begin{tabular}{|c|c|c|}
\hline $\begin{array}{c}\text { 17. SECURITY CLASSIFICATION } \\
\text { OF REPORT } \\
\text { Unclassified }\end{array}$ & $\begin{array}{c}\text { 18. SECURITY CLASSIFICATION } \\
\text { OF THIS PAGE } \\
\text { Unclassified }\end{array}$ & $\begin{array}{c}\text { 19. SECURITY CLASSIFICATION } \\
\text { OF ABSTRACT } \\
\text { Unclassified }\end{array}$ \\
\hline
\end{tabular}

NSN 7540-01-280-5500

Standard Form 298 (Rev. 2-89)

Prescribed by ANSI Std. Z39-18 298-102 

